\title{
Aplasia pura de células rojas y síndrome de Good. A propósito de un caso
}

\begin{abstract}
Ana Santos-Martínez, Rita García-Jiménez, María Gómez-Antúnez, Blanca Pinilla-Llorente, Antonio Muiño-Míguez Servicio de Medicina Interna. Hospital General Universitario Gregorio Marañón. Madrid. España
\end{abstract}

Recibido: 03/08/2018

Aceptado: 13/10/2018

En línea: 31/12/2018

Citar como: Santos-Martínez A, García-Jiménez R, Gómez-Antúnez M, Pinilla-Llorente B, Muiño-Míquez A. Aplasia pura de células rojas y síndrome de Good. A propósito de un caso. Rev Esp Casos Clin Med Intern (RECCMI). 2018 (Dic); 3(3): 113-114. doi: 10.32818/reccmi.a3n3a4.

Autor para correspondencia: María Gómez-Antúnez. mgantunez@salud.madrid.org

\section{Palabras clave \\ $\triangleright$ Timoma \\ $\triangleright$ Hipogammaglobulinemia \\ $\triangleright$ Aplasia pura de células rojas \\ $\triangleright$ Síndromes paraneoplásicos}

\section{Keywords \\ $\triangleright$ Thymoma \\ $\triangleright$ Agammaglobulinemia \\ $\triangleright$ Pure red-cell aplasia \\ $\triangleright$ Paraneoplastic syndromes}

\section{Resumen}

La asociación entre síndrome de Good y aplasia de células rojas es extremadamente rara. Presentamos el caso de una paciente con un timoma que presentaba concomitantemente estos dos síndromes paraneoplásicos. A pesar de la resección quirúrgica del timoma, ninguno de los dos trastornos autoinmunes mejoró.

Abstract
The association between Good's syndrome with pure red cell aplasia is extremely rare. We report a middle-aged
female patient with thymoma who developed concomitantly these two paraneoplastic syndromes. Despite perfo-
mance surgical resection thymoma, none of autoinmune disorders had improved.

\section{Puntos destacados}

$\triangleright$ En todo paciente con timoma, se debe descartar la presencia de miastenia gravis y tener una alta sospecha de aparición de otros síndromes paraneoplásicos, a la vez o después del diagnóstico de timoma y que pueden no mejorar con la timectomía.

\section{Introducción}

Los timomas son tumores del mediastino que se asocian frecuentemente con síndromes paraneoplásicos. De ellos, el más frecuente es la miastenia gravis (15\%), seguida por la hipogammaglobulinemia (5-10\%) y la eritroblastopenia o aplasia de células rojas (APCR) (5\%). En algunos casos, la extirpación quirúrgica del tumor es curativa.

Se describe el caso de una mujer de mediana edad diagnosticada de timoma que presentó de forma concomitante ambos trastornos autoinmunitarios: síndrome de Good y APCR.

\section{Historia clínica, exploración y pruebas complementarias}

Mujer de 58 años sin antecedentes médicos de interés, en tratamiento con venlafaxina por una depresión reactiva. La paciente refería historia de 3 sema- nas de evolución de astenia, hiporexia, pérdida de peso y episodios vespertinos de fiebre de hasta $38^{\circ} \mathrm{C}$, por lo que consulta con su médico de Atención Primaria, quien solicita analítica.

Acude a Urgencias remitida por su referido médico de Atención Primaria por presentar en la analítica $\mathrm{Hb}$ de $6,5 \mathrm{~g} / \mathrm{dl}$. En la exploración física, la paciente estaba estable hemodinámicamente, consciente, orientada, con palidez mucocutánea. Auscultación pulmonar normal y auscultación cardíaca con soplo sistólico en foco aórtico INI. Exploración abdominal normal, sin visceromegalias. No adenopatías palpables a ningún nivel.

Pruebas complementarias:

- Hemograma. Hb 6,5 g/dl (12-16), VCM 90,6 fl (80-98), CHCM 34 g/dl (32-36), plaquetas $49010^{3} / \mu \mathrm{l}(140-400)$, leucocitos $9,510^{3} / \mu \mathrm{l}$.

- Frotis de sangre periférica. Cayados $0 \%$, metamielocitos $0 \%$, segmentados $76 \%$, mielocitos $0 \%$, linfocitos $18 \%$, promielocitos $0 \%$, monocitos $6 \%$, blastos $0 \%$, eosinófilos $0 \%$, linfocitos atípicos $0 \%$, basófilos $0 \%$, eritroblastos $0 \%$ en 100 leucocitos, reticulocitos $10.100 / \mu$ l. No rasgos displásicos.

- Bioquímica. Ferritina 4.325 g/l (12-200), índice de saturación de transferrina 95\% (15-45\%).

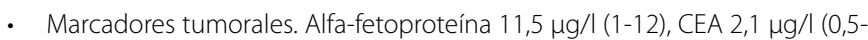
7,0), antígeno CA-125 $48 \mathrm{U} / \mathrm{ml}$ (5-35), antígeno CA-15-3 $10 \mathrm{U} / \mathrm{ml}$ (1-30), antígeno CA-19-9 $17 \mathrm{U} / \mathrm{ml}$ (2-37), CYFRA 21-1 2,0 $\mu \mathrm{g} / \mathrm{l}$ (0,1-3,3), calcitonina $<2,0 \mathrm{ng} / \mathrm{l}$.

- Inmunología. IgG 425,0 mg/dl (650-1.610), IgA 46,1 mg/dl (85-468), IgM $30,1 \mathrm{mg} / \mathrm{dl}$ (45-276), complemento C3 170,0 mg/dl (92-193), C4 25,6 mg/ dl (18-57). Ac. antirreceptor colinérgico negativo. Ac. anti-MuSK negativo. 
- Microbiología. Cuantificación ADN VHB (PCR) 33.987.450 UI/ml (178.773.987 copias/ml).

- Estudio de mutaciones del gen HFE. Heterocigota para el gen H63D de hemocromatosis.

- Radiografía de tórax. Masa mediastínica anterior.

- Tomografía axial computarizada (TAC) torácica. Tumoración mediastínica anterior de unos $8,8 \times 6 \times 9,8 \mathrm{~cm}$ sugestiva de timoma sin datos de infiltración de estructuras vasculares mediastínicas. Infiltrado en vidrio deslustrado en segmento 6 derecho.

- Anatomía patológica de biopsia de masa mediastínica. Cilindros correspondientes íntegramente a un timoma tipo A (clasificación de la OMS), con áreas fusocelulares y formación de ovillos y áreas solidas, sin apreciarse imágenes de angioinvasion ni de invasión tisular.

- Aspirado de médula ósea. Parénquima medular normocelular (3/5), hiperplasia granulocítica y eritroblastopenia selectiva.

- Biopsia hepática. Parénquima hepático de arquitectura preservada, citólisis leve, inflamación linfocitaria inespecífica y siderosis leve-moderada. Tinción IHQ para Ag core y surface del VHB positivos en numerosos hepatocitos.

\section{Evolución}

La paciente recibió tratamiento antiviral con entecavir, primero, y después tenofovir. Fue intervenida quirúrgicamente de su timoma y de la lesión pulmonar. El resultado de la anatomía patológica fue timoma tipo A, que respeta los márgenes quirúrgicos de resección y adenocarcinoma pulmonar no mucinoso mínimamente invasivo.

Unos meses después, precisó ingreso en UVI por neumonitis intersticial linfoide, tratada con esteroides y rituximab. Durante el ingreso, presentó múltiples complicaciones: traqueobronquitis purulenta por Streptoccocus viridans, trombosis de la vena cava superior, bacteriemia por Acinetobacter baumanii, trombopenia grave relacionada con rituximab y enfermedad neuromuscular del paciente crítico.

Un año después de la extirpación quirúrgica, presentó un episodio de neutropenia de origen central que fue tratada con prednisona y ciclosporina.

La eritroblastopenia y la hipogammaglobulinemia asociadas al timoma no mejoraron tras la extirpación de éste, por lo que se pautó tratamiento con ciclosporina y administración de inmunoglobulinas cada 3 semanas.

\section{Diagnóstico}

- Timoma tipo A.

- Síndrome de Good.

- Eritroblastopenia.

- Adenocarcinoma pulmonar no mucinoso.

- Hepatopatía por virus de la hepatitis B.

\section{Discusión y conclusiones}

Los síndromes paraneoplásicos se asocian frecuentemente con timomas sin embargo la asociación de síndrome de Good y APCR es extremada- mente infrecuente, habiéndose descrito alrededor de 20 casos en la literatura ${ }^{1-3}$.

El síndrome de Good fue descrito inicialmente por el Dr. Good como una hipogammaglobulinemia relacionada con timoma ${ }^{4}$. Se caracteriza por células B ausentes o disminuidas en sangre periférica, hipogammaglobulinemia y defectos en la inmunidad celular ${ }^{5}$. Estos pacientes tienen una elevada susceptibilidad a infecciones bacterianas, virales, micóticas e infecciones oportunistas ${ }^{6}$, siendo la tasa de mortalidad elevada. Afecta a ambos sexos por igual, y es más frecuente en adultos mayores. La resección del tumor, en general, no mejora la inmunodeficiencia ${ }^{6}$, y las inmunoglobulinas intravenosas son el tratamiento de elección? 7 . De forma habitual, el diagnóstico del timoma precede al de la hipogammaglobulinemias.

La APCR se caracteriza por anemia severa normocítica, normocrómica, arregenerativa y ausencia absoluta de eritroblastos en la médula ósea, con normalidad de las otras series hematopoyéticas. Como en nuestro caso, suele ser diagnosticada en un periodo cercano al diagnóstico de timoma ${ }^{6}$. Es causada por una reacción inmunológica anormal contra los precursores eritroides en la médula ósea. Se ha descrito completa remisión en el 30\% de pacientes con timoma y APCR, tras timectomía ${ }^{7}$. En pacientes con APCR resistentes tras resección quirúrgica, el tratamiento adyuvante se basa en drogas inmunosupresoras y soporte transfusional ${ }^{6}$. No se conoce bien la relación causal, aunque se cree que el timo puede producir algún factor inhibidor, o células T supresoras que inhiban la eritropoyesis ${ }^{8}$.

El manejo inicial suele ser la extirpación quirúrgica del timoma, aunque esto no siempre conlleva resolución del síndrome paraneoplásico, pudiendo requerir tratamientos adicionales para el mismo, como la administración periódica de inmunoglobulinas intravenosas en el caso de hipogammaglobulinemia4.

\section{Bibliografía}

1. Lin CS, Yu YB, Hsu HS, Chou TY, Hsu WH, Huang BS. Pure red cell aplasia and hypogammaglobulinemia in a patient with thymoma. J Chin Med Assoc. 2009 Jan; 72(1): 34-38. doi: 10.1016/S1726-4901(09)70017-6.

2. Murray WD, Webb JN. Thymoma associated with hypogammaglobulinaemia and pure red cell aplasia. Am J Med. 1966; 41: 974-980.

3. Tsai YG, Lai JH, Kuo SY, Chen HC, Chang DM. Thymoma and hypogammaglobulinemia (Good's syndrome): a case report. J Microbiol Immunol Infect. 2005; 38: 218-220.

4. Kelleher P, Misbah SA. What is Good's syndrome? Immunological abnormalities in patients with thymoma. J Clin Pathol. 2003; 56: 12-16.

5. Briones J, Iruretagoyena M, Galindo H, et al. Thymoma associated with hypogammaglobulinaemia and pure red cell aplasia. Ecancermedicalscience. 2013 Oct 17; 7: 364. doi: 10.3332/ecancer.2013.364.

6. Peña C, Intriago M, Muñoz P, Gray AM, Cabrera ME. Síndrome de Good y aplasia pura de la serie roja, reporte de un caso y revisión de la literatura: report of one case. Rev. Méd. Chile. 2012 Aug; 140(8): 1050-1052. doi: 10.4067/S0034-98872012000800013.

7. Taniguchi T, Usami N, Kawaguchi K, Yokoi K. Good syndrome accompanied by pure red cell aplasia. Interact Cardiovasc Thorac Surg. 2009 Oct; 9(4): 750-752. doi: 10.1510/icvts.2009.210393.

8. Zoumbos NC, Gascón P, Djeu JY, Trost SR, Young NS. Circulating activated suppressor T lymphocytes in aplastic anemia. N Engl J Med. 1985; 312: 257-265. 